\title{
"Loading-type" Plasmonic Nanoparticles for Detection of Peroxynitrite in Living Cells
}

\author{
Jin Wang ${ }^{1}$, Xiang-Ling Li ${ }^{1,2 *}$, Hong-Yuan Chen ${ }^{1}$, Jing-Juan $\mathrm{Xu}^{1 *}$
}

\begin{abstract}
${ }^{1}$ State Key Laboratory of Analytical Chemistry for Life Science, School of Chemistry and Chemical Engineering, Nanjing University, Nanjing 210023, P.R. China.

${ }^{2}$ College of Life Science and Pharmaceutical Engineering, Nanjing Tech University, Nanjing 211816, P.R. China.

*Corresponding author: Tel/ fax: +86-25-89687924, Email: xlli@njtech.edu.cn. (X.-L. Li), xujj@nju.edu.cn (J.-J. Xu)
\end{abstract}

\section{Table of contents}

1. Synthesis and the characterization of $\mathrm{CHCN}$ S2

2. Characterization of the prepared AuNPs and Au@MSN-CHCN S3

3. Quantification of the CHCN loaded on each probe. S-4

4. The stability assessment of $\mathrm{Au} @ \mathrm{MSN}-\mathrm{CHCN}$ S-5

5. Assessment of the feasibility of the nanoprobes to detect $\mathrm{ONOO}^{-}$ S-6

6. Evaluation of the selectivity behavior of $\mathrm{Au@MSN-CHCN}$ for ONOO- detection S-7

7. The biocompatibility evaluation of Au@MSN-CHCN. S-8

8. Exogenous $\mathrm{ONOO}^{-}$detection in MCF-7 cells. S-8

9. Reference S-9 


\section{Synthesis and the characterization of $\mathrm{CHCN}$}

CHCN was prepared according to the procedures illustrated in Scheme S1. Diethylaminocoumarin-3-aldehyde (50 mg, $2 \mathrm{mmol}$ ) and 1,3,3-trimethyl-2-methyl-eneindoline (60 mg, $2 \mathrm{mmol}$ ) were dissolved in absolute ethanol $(20 \mathrm{~mL})$ and refluxed for $10 \mathrm{~h}$. After cooling to room temperature, ethanol was removed under reduced pressure. The corresponding solid was further purified by silica gel column chromatography using DCM/Methanol (20/1, v/v) as eluent to afford $\mathrm{CHCN}$ as a deep violet solid. HRMS: $\left[\mathrm{M}^{+}\right]$at 401.25 (Figure S1). ${ }^{1} \mathrm{H}$ NMR spectra is shown in Figure S2 $\left(300 \mathrm{MHz}, \mathrm{CDCl}_{3}-\mathrm{d}_{3}\right) \delta 10.05(\mathrm{~s}, 1 \mathrm{H}), 8.60(\mathrm{~d}, \mathrm{~J}=16.2 \mathrm{~Hz}, 1 \mathrm{H}), 8.13(\mathrm{~d}, \mathrm{~J}=9.3 \mathrm{~Hz}, 1 \mathrm{H}), 8.10$ (d, J=16.2 Hz, 1H), 7.52-7.63 (m, 4H), $6.72(\mathrm{dd}, \mathrm{J}=9.3 \mathrm{~Hz}, 1 \mathrm{H}), 6.47$ (s, 1H), 4.31 (s, 3H), 3.54 (q, J=7.1 Hz, 4H), $1.85(\mathrm{~s}, 6 \mathrm{H}), 1.34(\mathrm{t}, \mathrm{J}=7.1 \mathrm{~Hz}, 6 \mathrm{H})$.<smiles>CCN(CC)c1ccc2cc(C=O)c(=O)oc2c1</smiles><smiles>Cc1c(C)n(C)c2ccccc12</smiles>
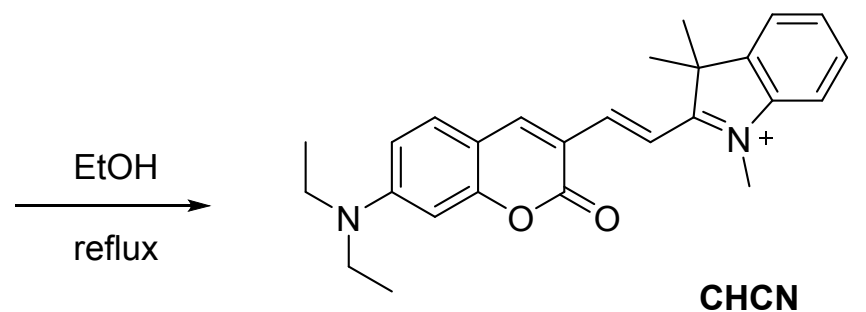

Scheme S1 Synthetic pathway of CHCN

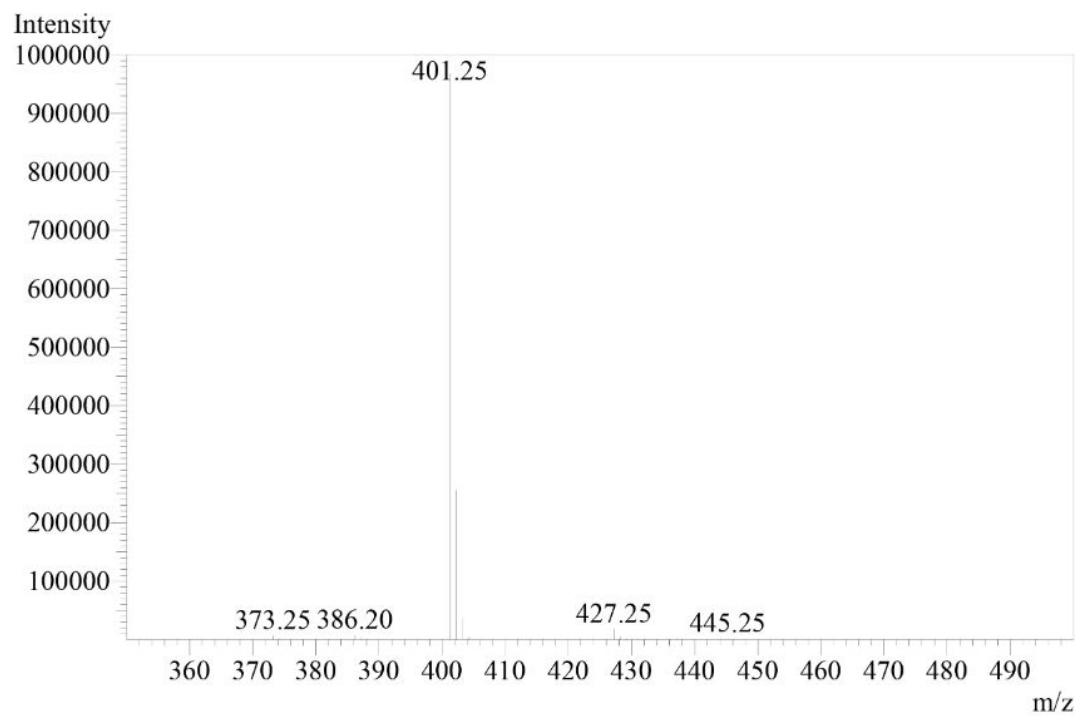

Figure S1 HRMS spectrum of CHCN 




Figure S2 ${ }^{1} \mathrm{H}$ NMR spectrum of $\mathrm{CHCN}$

\section{Characterization of the prepared AuNPs and Au@MSN-CHCN}

Transmission electron microscopy (TEM) images revealed that the synthesized AuNPs were smooth and spherical with a uniform diameter of $38.5 \mathrm{~nm}$. After the growth of mesoporous silica shells with radial pores, the AuNPs were uniformly covered by mesoporous silica shells with an average diameter of $60 \mathrm{~nm}$ (Figure S3). And then MPTMS was further employed to improve the stability of the as-synthetic Au@MSN, the modification process was characterized by the zeta potential analysis (Figure S4A), UV-vis measurement (Figure S4B) and dynamic light scattering (DLS) characterization (Figure S5).
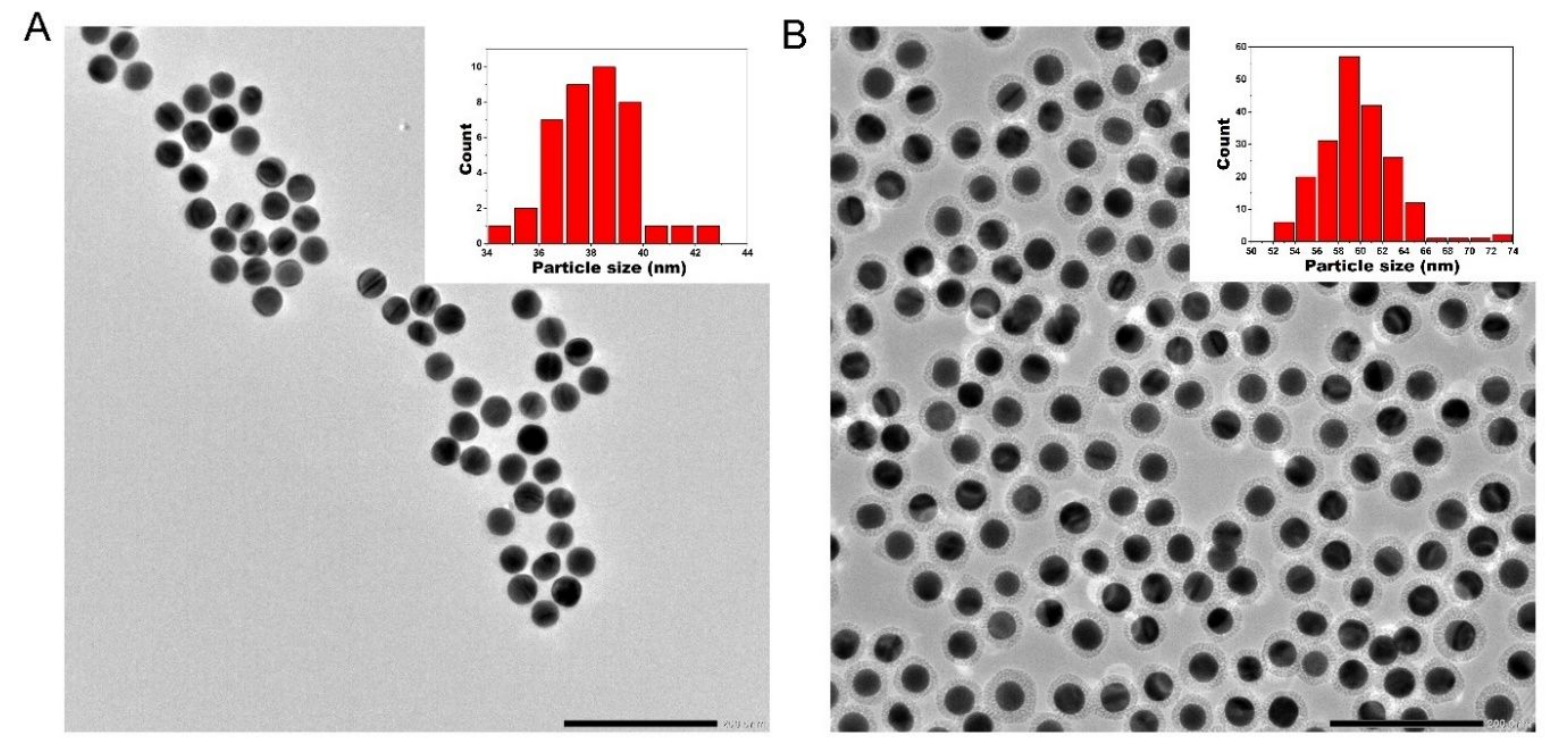

Figure S3 TEM characterization of AuNPs core (A) and Au@MSN (B). Inset: the corresponding particle size distribution histogram. 

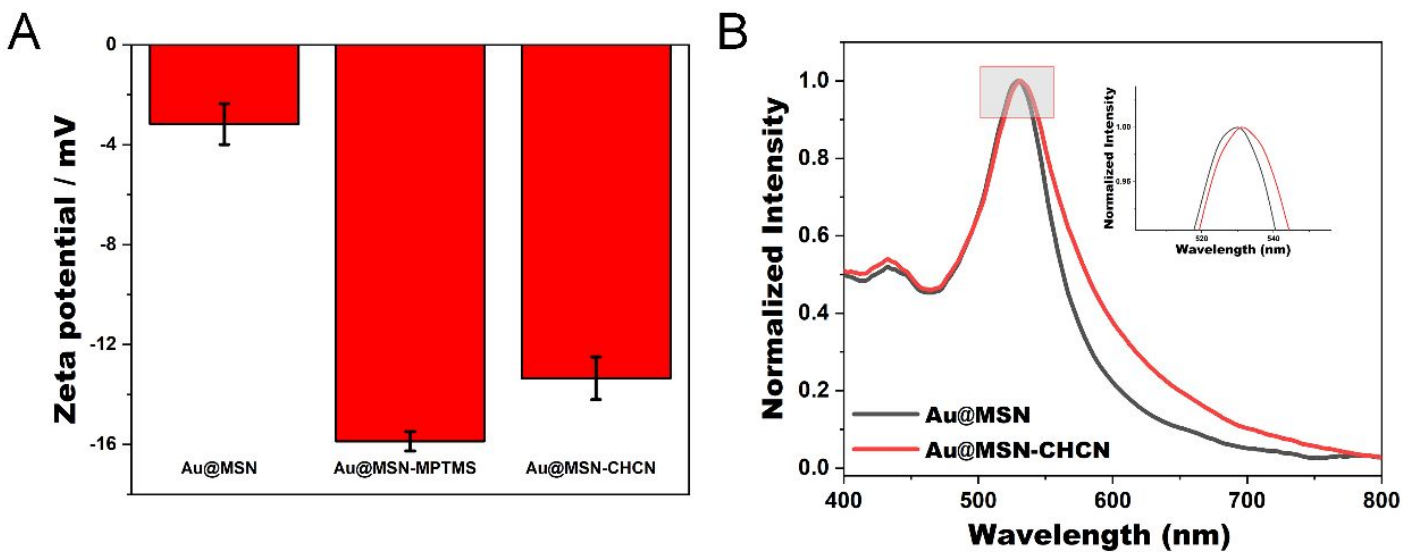

Figure S4 (A) Zeta potential of Au@MSN, Au@MSN-MPTMS, and Au@MSN-CHCN. (B) UV-vis spectra of Au@MSN and Au@MSN-CHCN nanoparticles.
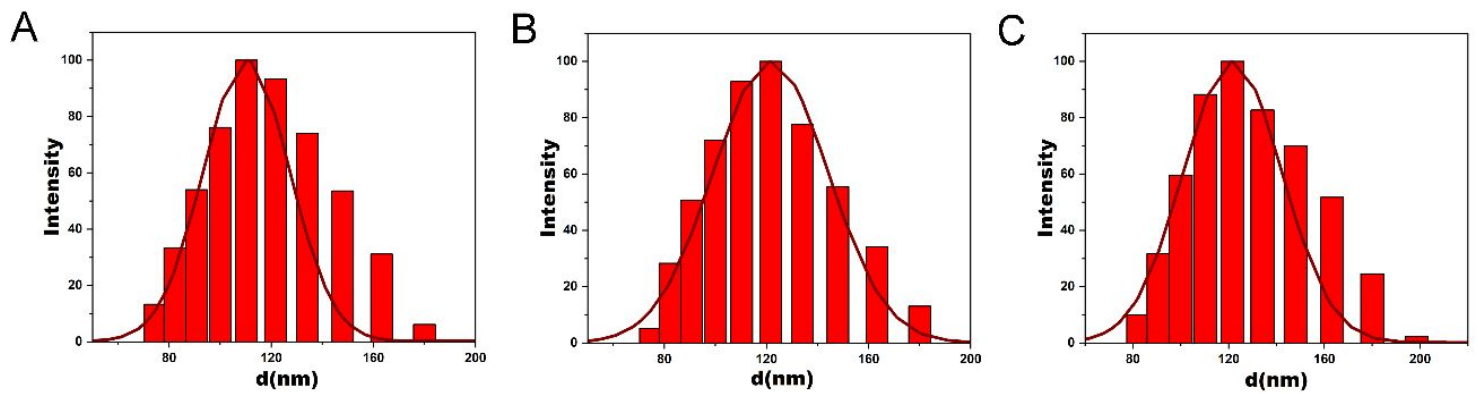

Figure S5. DLS characterization of the prepared Au@MSN (A), Au@MSN-MPTMS (B) and Au@MSN$\mathrm{CHCN}(\mathrm{C})$.

\section{Quantification of the CHCN loaded on each probe}

The amount of CHCN loaded on each probe was measured by the following method. The concentration of the nanoparticle could be calculated according to the Beer-Lambert Law, $\mathrm{A}=\varepsilon \cdot \mathrm{c} \cdot 1$, while the extinction coefficient is ca. $8.19 \times 10^{9} \mathrm{M}^{-1} \mathrm{~cm}^{-1}$ at $\lambda_{527}$ for $38.5 \mathrm{~nm} \mathrm{AuNPs}^{1}$. As shown in Figure S6A, the absorption value of the 527$\mathrm{nm}$ plasmon peak is $\sim 1.09$, so the concentration is $\sim 133.1 \mathrm{pM}$. Then, $10 \mathrm{~mL} \mathrm{Au} @ \mathrm{MSN}$ was synthesized using $5 \mathrm{~mL}$ AuNPs as seeds, ignoring the slight loss that may exist in the synthesis process, the concentration of $\mathrm{Au} @ \mathrm{MSN}$ was calculated to be $66.5 \mathrm{pM}$ based on the concentration of AuNPs.

The fluorescence intensity of a series of concentrations of $\mathrm{CHCN}$ was detected to establish a calibration curve 
(Figure S6B). As the concentration of $\mathrm{CHCN}$ increased, the fluorescence intensity was enhanced linearly from 0.1 to $10 \mu \mathrm{M}, \mathrm{I}_{\mathrm{F}}=-196.14+364.97 \times \mathrm{C}_{\mathrm{CHCN}}(\mu \mathrm{M})$. Then, $\mathrm{CHCN}$ was brought to the probe solution to achieve a final concentration of $10 \mu \mathrm{M}$. After incubated $24 \mathrm{~h}$ with shaking, the obtained $\mathrm{Au} @ \mathrm{MSN}-\mathrm{CHCN}$ were centrifuged at $8000 \mathrm{rpm}$ for $8 \mathrm{~min}$, and fluorescence intensity of the supernatant was measured to be $\sim 1009$ (Figure S6C) and the concentration was $3.3 \mu \mathrm{M}$ calculated by the above linear equation. Then the $\mathrm{CHCN}$ concentration retained in the nanocarriers was estimated to be $6.7 \mu \mathrm{M}$ and the number of CHCN loaded on each Au@MSN-CHCN was calculated to be $\sim 1.01 \times 10^{5}$ by the following formula:

$$
N=\frac{c_{C H C N}}{c_{A u @ M S N}}
$$

$\mathrm{N}$ : the number of $\mathrm{CHCN}$ molecules loaded by per nanoparticle.
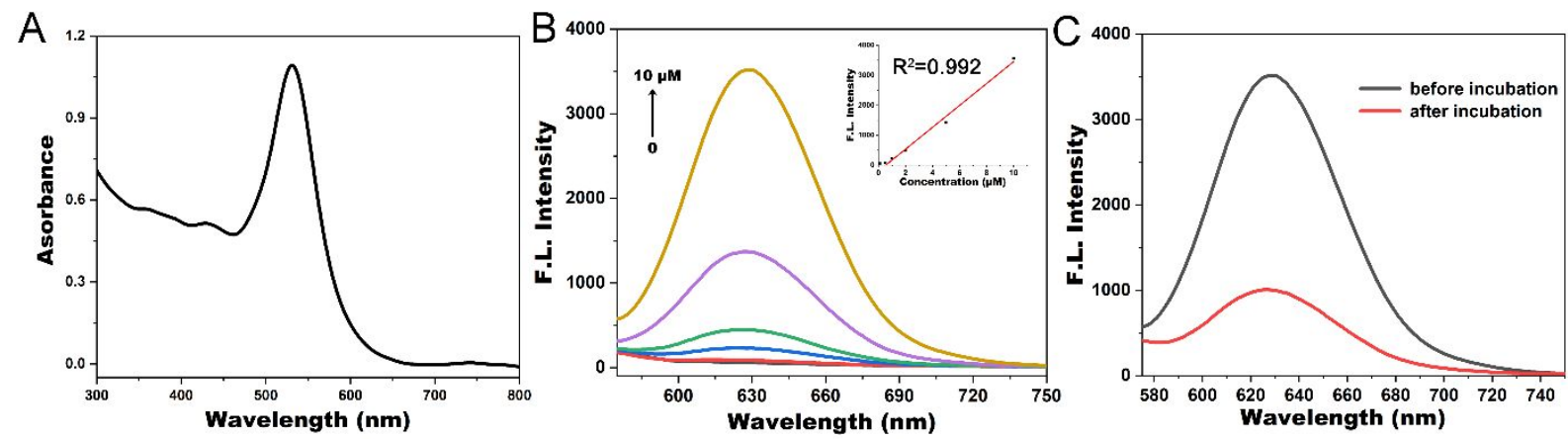

Figure S6 (A) UV-vis spectrum of the synthesized $38.5 \mathrm{~nm}$ AuNPs. (B) Fluorescence spectra of different concentrations of $\mathrm{CHCN}(0.1,0.5,1,2,5,10 \mu \mathrm{M}$, respectively), the inserted curve is the linear relationship between intensity and concentration. (C) Fluorescence emission spectra of the $\mathrm{CHCN}$ solution before and after incubation with $\mathrm{Au} @ \mathrm{MSN}\left(\lambda_{\mathrm{ex}}=560 \mathrm{~nm}, \lambda_{\mathrm{em}}=517 \mathrm{~nm}\right)$.

\section{The stability assessment of Au@MSN-CHCN}

The stability of nanoprobes was tested. As seen in Figure S7, even dispersed in PBS after $16 \mathrm{~h}$, the morphology and the scattering intensity of $\mathrm{Au} @ \mathrm{MSN}-\mathrm{CHCN}$ had no obvious change, indicating that $\mathrm{Au} @ \mathrm{MSN}-\mathrm{CHCN}$ had good structural stability, and $\mathrm{CHCN}$ molecules were successfully encapsulated in mesoporous silicon without obvious leakage. 


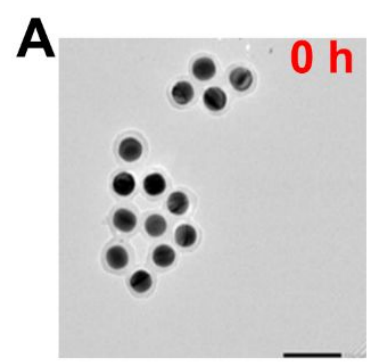

B
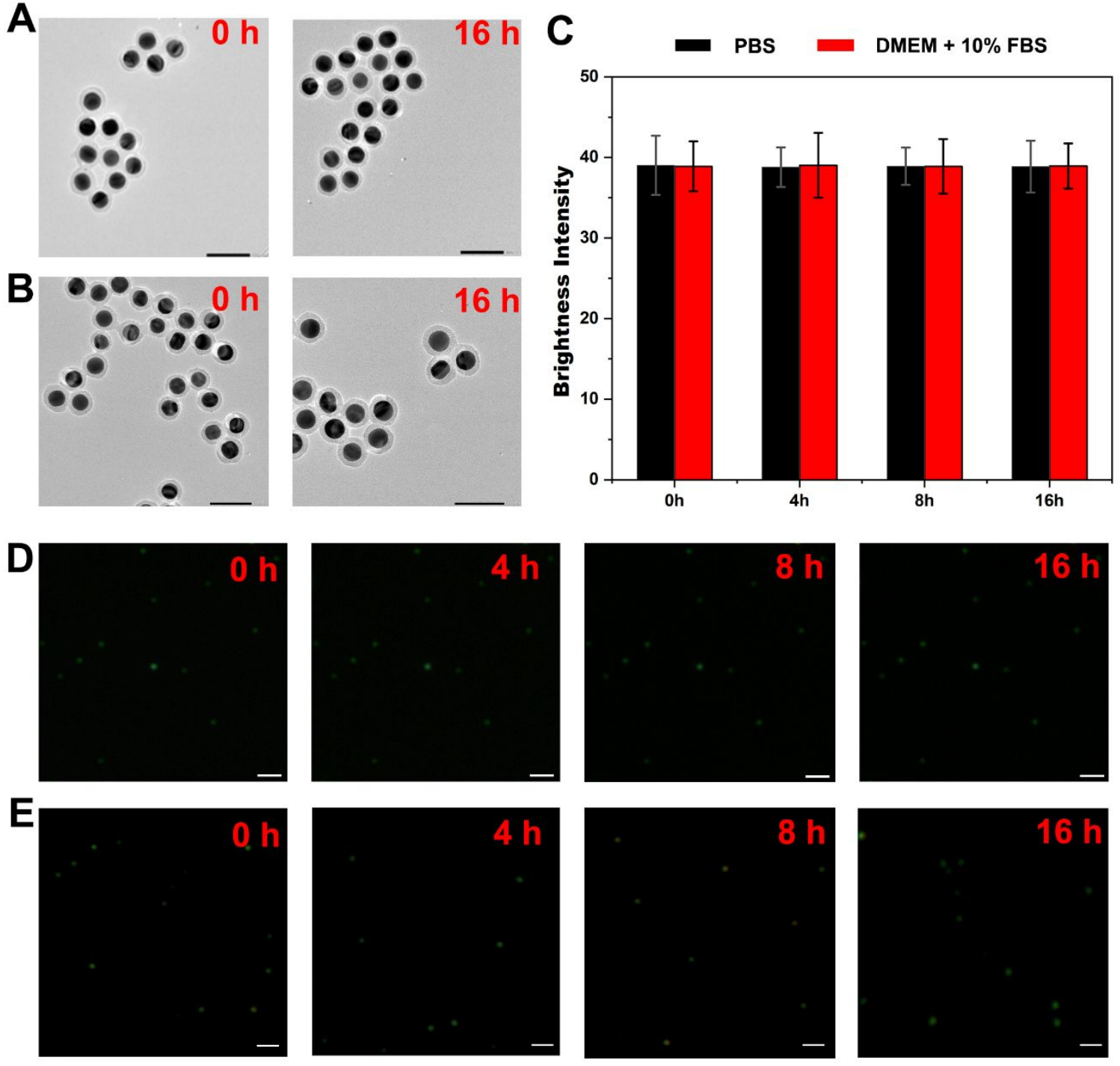

Figure S7 (A) TEM and (D) DFM characterization of Au@MSN-CHCN dispersed in PBS at different time points. (B) TEM and (E) DFM characterization of Au@MSN-CHCN dispersed in DMEM + 10\% FBS at different time points. The scar bar is $100 \mathrm{~nm}$ for TEM and $2 \mu \mathrm{m}$ for DFM. (C) The corresponding brightness intensity analysis of particles in (D) and (E).

\section{Assessment of the feasibility of the nanoprobes to detect $\mathrm{ONOO}^{-}$}

The reaction mechanism of $\mathrm{CHCN}$ for $\mathrm{ONOO}^{-}$was illustrated in Scheme S2. The bridging double bond of CHCN could be oxidized by $\mathrm{ONOO}^{-}$, leading to destruction of the extended conjugation. It is confirmed by Figure S8, 
as the concentration of added $\mathrm{ONOO}^{-}$increases, the absorption peak of $\mathrm{CHCN}$ at $560 \mathrm{~nm}$ gradually decreases until it disappears, indicating that the reaction product of $\mathrm{CHCN}$ and $\mathrm{ONOO}^{-}$loses the corresponding conjugated structure.<smiles>CCC[N+]1=C(/C=C/c2cc3ccc(N(CC)CC)cc3oc2=O)C(C)(C)c2ccccc21</smiles>

Scheme S2. The reaction mechanism of $\mathrm{CHCN}$ for $\mathrm{ONOO}^{-}$

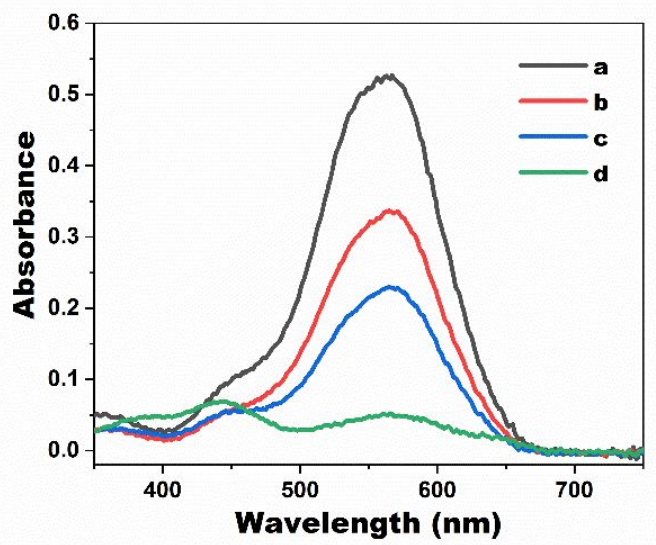

Figure S8 UV-vis spectra of $\mathrm{CHCN}(0.5 \mathrm{mM})$ after the addition of $\mathrm{ONOO}^{-}(\mathbf{a} 0 \mathrm{mM}, \mathbf{b} 0.05 \mathrm{mM}, \mathbf{c} 0.2 \mathrm{mM}, \mathbf{d}$ $1 \mathrm{mM}$ ) in PBS buffer solution ( $\mathrm{pH}$ 7.4).

\section{Evaluation of the selectivity behavior of $\mathrm{Au} @ \mathrm{MSN}-\mathrm{CHCN}$ for $\mathrm{ONOO}^{-}$detection}

The selectivity behavior of the $\mathrm{Au} @ \mathrm{MSN}-\mathrm{CHCN}$ was evaluated by incubating with target $\mathrm{ONOO}^{-}$or other analogues, such as $\mathrm{H}_{2} \mathrm{~S}, \mathrm{H}_{2} \mathrm{O}_{2}, \mathrm{NO}, \mathrm{NO}^{2-}$, t-BuOOH, Cys, $\mathrm{Hcy}, \mathrm{GSH}, \mathrm{K}^{+}, \mathrm{Na}^{+}$, and $\bullet \mathrm{OH}$ (5 equiv for $\mathrm{H}_{2} \mathrm{O}_{2}$ and -OH; 100 equiv for other species).. The result showed that after adding other analogous analytes to our probe no significant increase in scattering intensity was observed, indicating that the Au@MSN-CHCN has excellent selectivity for the target ONOO-. 


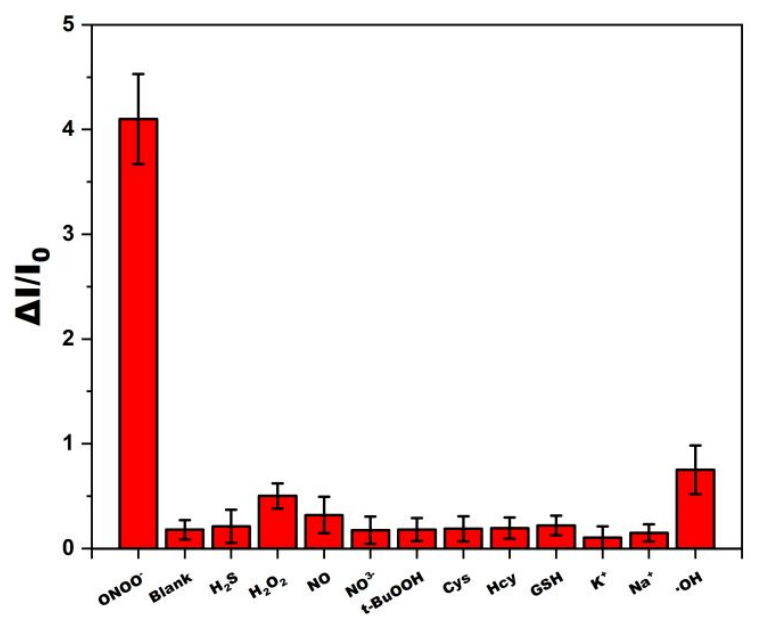

Figure S9 The scattering signal changes of $\mathrm{Au} @ \mathrm{MSN}-\mathrm{CHCN}$ in the presence of $\mathrm{ONOO}^{-}$and other analogous analytes: $\mathrm{H}_{2} \mathrm{~S}, \mathrm{H}_{2} \mathrm{O}_{2}, \mathrm{NO}, \mathrm{NO}^{2-}$, t-BuOOH, Cys, $\mathrm{Hcy}, \mathrm{GSH}, \mathrm{K}^{+}, \mathrm{Na}^{+}$, and $\bullet \mathrm{OH}$.

\section{The biocompatibility evaluation of Au@MSN-CHCN}

The cytotoxicity of the nanoprobe was determined by MTT assay with HeLa cells. As exhibited in Figure S10, even cultured for $48 \mathrm{~h}$, the probes had no obvious effect on the viability of HeLa cells at a concentration of the nanoprobe no more than $10 \mathrm{pM}$.

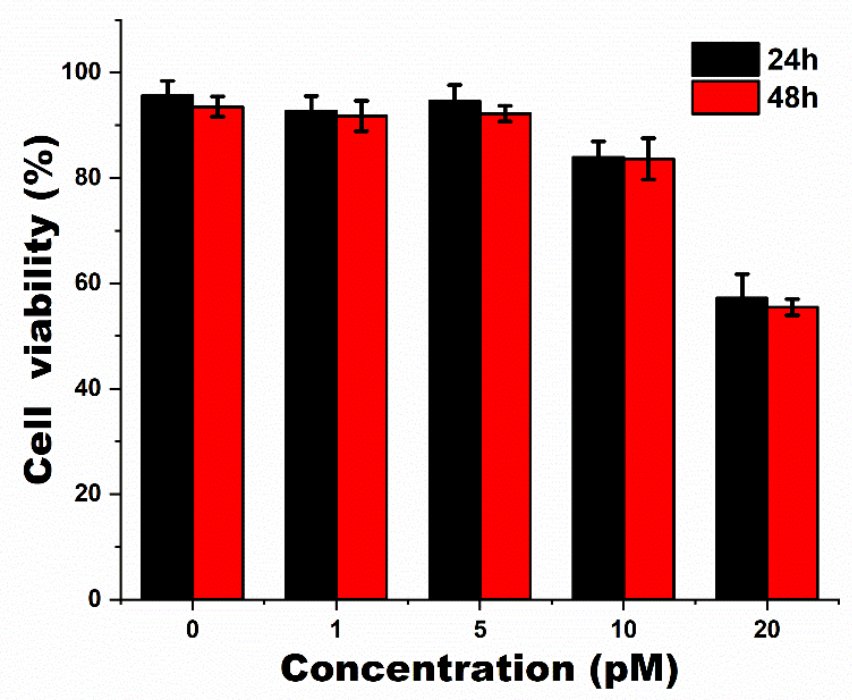

Figure S10 HeLa cells were incubated with different concentrations of the nanoprobes for $24 \mathrm{~h}$ and $48 \mathrm{~h}$, 
respectively.

\section{Exogenous $\mathrm{ONOO}^{-}$detection in $\mathrm{MCF}-7$ cells}

To verify the universality of the nanoprobes $\mathrm{Au} @ \mathrm{MSN}-\mathrm{CHCN}$, the detection of ONOO- in MCF-7 cell line was performed under the same condition of HeLa cells. As shown in Figure S11, a same enhanced trend of scattering signal of nanoprobes also appeared in the MCF-7 cells.
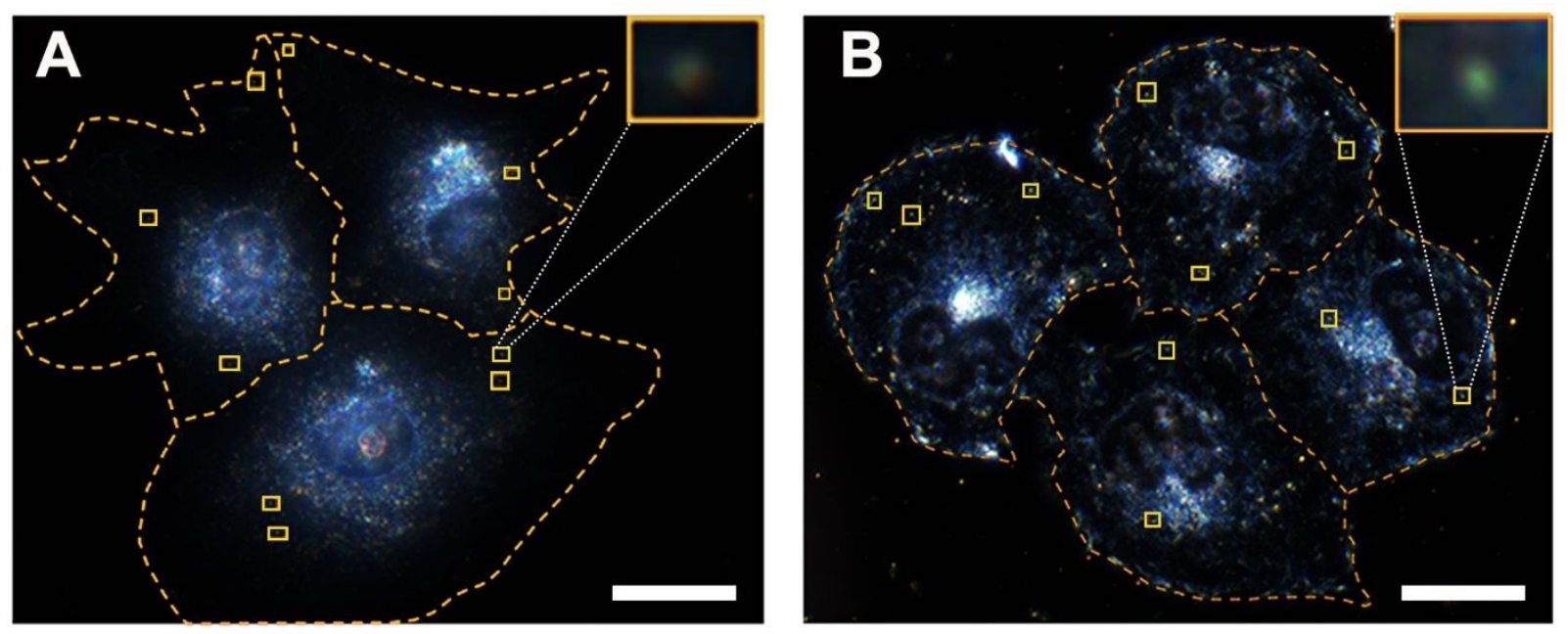

Figure S11 Dark-field images of MCF-7 cells incubated with Au@MSN-CHCN before (A) and after (B) incubation with $20 \mu \mathrm{M} \mathrm{ONOO}^{-}$for $0.5 \mathrm{~h}$. Inset: magnified views of single nanoprobe image in the cell. The scar bar is $10 \mu \mathrm{m}$.

\section{Reference}

1. W. Haiss, N. T. Thanh, J. Aveyard and D. G. Fernig, Anal. Chem., 2007, 79, 4215-4221. 